\section{In tern ationa l \\ Journal of}

Medical

and Surgical Sciences

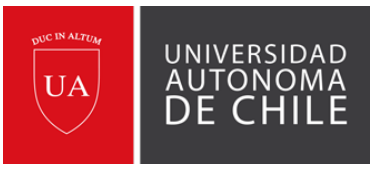

\title{
Factors associated with Oral Health Related Quality of Life in children. Literature Review.
}

\author{
Yanara Nauduam ${ }^{1} \&$ Gabriela Sandoval. ${ }^{1}$
}

\section{ABSTRACT}

Quality of Life (QoL) refers to a concept that might comprise different levels, which are able to identify the biological, economic, social and psychological demands from individual level up to community level. The concept of oral health-related quality of life (OHRQoL) refers to the ability of performing daily activities and considers subjective aspects such as happiness, social well-being and emotional well-being, in order to know people's perception about their life. The aim of this article is to review the main factors associated with OHRQoL in children. Socioeconomic status, family structure, overcrowded homes, number of children, parent's educational attainment and psychological factors, among others, were significant predictors for children's OHRQoL. In Chile, there is a scarcity of OHRQoL in children and adolescents. The knowledge of OHRQoL might help to improve the development of programs and the effectiveness of oral health services, since it allows the assessment of small children, perceived needs and effectiveness of treatment strategies.

Keywords: children; quality of life; oral health; oral health related quality of life.

\section{INTRODUCTION}

Currently, Quality of Life (QoL) refers to a concept that might comprise different levels, which are able to identify the biological, economic, social and psychological demands from individual level up to community level. According to the WHO, QoL is the perception that an individual has in their existing position, in the context of the culture and value system in which they live and concerning their goals, expectations, norms and worries (Galván, 2015). QoL is equivalent to the sum of all the scores of the life conditions that are objectively measurable in a person, such as: physical health, life conditions, social relations, functional activities or occupation (Urzúa \& Caqueo, 2012). There aren't universal parameters for a good or optimal QoL, since the standards used for its assessment are different depending on the individual and the society. QoL is considered as a synonym of personal satisfaction.

QoL improves as the level of education is higher. The results are significant concerning lower class populations, where school education is likely to bring more satisfaction, compared to populations with other social classes. On the other hand, there seems to be a noteworthy similarity among satisfaction reports from subjects of different ages. However, there are some statistically significant differences regarding gender. Regarding satisfaction with life during adolescence, males report a higher physical and psychological well-being, better relations with their parents and autonomy, as well as greater satisfaction with life than females.

Definitions like QoL and health emphasize that QoL as well as Health-Related QoL (HRQOL) are influenced by a complex interaction of biological and social determiners. These two concepts are closely related because of their impact on oral health or oral conditions, since they might interfere with a person's daily performance. The limits of the definition depend generally on the reason why health is being evaluated, as well as the particular concerns of patients, doctors and researchers. We use the term HRQoL 
since there are highly valued aspects of life that are generally not considered "health", including income, freedom and quality of the environment. Although lower or unstable income, lack of freedom or a low quality environment may have a negative effect on health, these problems are often far from the medical or health care concerns (Åkesson et al., 2016).

The mouth plays key roles such as: facial expression, language, chewing, swallowing, salivation and sense of taste. It appears as a good indicator of the individual's health, their QoL, and their individual and social well-being, thus considerably improving factors such as self-esteem, esthetics, social interaction and emotional state. In the case of children, there are several studies on preschool children's oral health, due to the high prevalence of oral conditions in this group, such as dental caries, dental trauma and malocclusion (Kramer et al., 2013). Researchers, as well as oral health politicians, have recognized that the assessment of oral health results is vital for planning oral health programs. Therefore, the assessment of the relation between QoL and oral health plays a key role in the planning of new policies (Basavaraj et al., 2013).

The concept of oral health-related quality of life (OHR$Q o L)$ refers to the ability of performing daily activities and considers subjective aspects such as happiness, social well-being and emotional well-being, in order to know people's perception about their life (Cancio et al., 2018). From the dental area, oral conditions, such as dental caries and periodontal disease, have a multifactorial etiology that is not only due to biological factors, but also to environmental, social and cultural factors that influence attitudes and behaviors in terms of oral health (Born et al., 2018). It is worth mentioning that there is a strong relation between family and a child's oral health, due to early childhood behaviors and parental factors that are predictive of caries prevalence in permanent dentition (Kragt et al., 2018).

The aim of this article is to review the main factors associated with OHRQoL in children.

\section{FACTORS ASSOCIATED WITH OHRQOL IN CHILDREN}

Previous studies conducted in Brazil showed that families with children that presented six or more caries lesions (high severity) were approximately seven times more likely to have an impact on their QoL. This might be due to the fact that the progression of caries implies a more complicated treatment, which might result in the loss of working days for parents and financial problems for the family. Additionally, the severity of caries often results in an antiesthetic appearance, which might cause concerns for parents/caregivers about the child's future life opportunities (Firmino et al., 2016).
The negative impact of childhood dental caries includes the experience of feeling pain, difficulty for chewing or sleeping, loss of appetite, loss of weight, changes in behavior (irritability and low self-esteem), frequent non-attendance to school and/ or decrease of school performance (Monte-Santo et al., 2018). Children with severe caries declared more frequently that they felt sad about their teeth, compared to children without caries (Feitosa et al., 2005). Children with untreated early childhood caries showed significantly worse OHRQoL than children without them, assessed by children themselves as well as by their parents (Sheiham, 2006). Additionally, parents/caregivers often only recognize an oral health condition in their children when pain is involved (Perazzo et al., 2016). Because of this, regular visits to the dentist are one of the main forms of guaranteeing quality oral health and OHRQOL. By bringing children to dentists at an early age they might, in advance, guide oral hygiene practices, correct inadequate eating habits and instruct the parents/ caregivers in terms of health (Perazzo et al., 2016).

The esthetic improvement in malocclusion provides an increase in OHRQoL, particularly in psychological discomfort and psychological disability. It is reasonable to assume that the aspects of physical appearance play a key role in malocclusion, since it is an esthetic deviation from the ideal normal occlusion. Another study showed a significant correlation between eating discomfort (an aspect of physical discomfort) and malocclusion (Ashari \& Mohamed, 2016). Open bite was associated with a negative impact on preschoolers' OHRQoL, causing functional limitations, such as difficulty for eating, pronouncing words, affecting the perception of the own image and social interaction (Correa et al., 2016).

On the other hand, the developmental defects of the enamel (DDE), resulting in alterations that affect the stages of enamel development, are classified according to a clinical examination as hypoplasia or enamel opacities. DDEs present a high prevalence in primary dentition. This condition might have a negative esthetic effect and cause discoloration problems, tooth sensitivity, susceptibility to caries and dental attrition, which may affect OHRQoL. Discomfort is mainly related to cases of hypoplasia, where the enamel is absent or fractured (Correa et al., 2016).

Sociodemographic factors, income levels and lower levels of education are strictly related to the families' hygiene and poor nutrition. Likewise, the unpleasant experiences caused by early childhood caries, for parents and children, have an impact on the QoL of the individuals (De Melo et al., 2016).

At preschool stage, children depend on their parents/ caregivers for the prevention of oral conditions and the use of 
dental services. Factors such as parents/caregivers' higher level of schooling and household income are significant for QoL since they promote the use of dental services by children (Perazzo et al., 2016). Additionally, some studies address the fact that parents that are sensitive to their children's needs might contribute to establish adequate behaviors, such as eating healthier and being more physically active, than parents that are less sensitive to their children's needs (Kumar et al., 2017).

The perception of responsibility for children's oral health might be influenced by socioeconomic status, while oral health status might have an impact on the child's QoL, regardless of socioeconomic status (Vollu, 2018). The involvement of mothers in their children's school activities had a positive influence on the use of dental care. Involved mothers were more likely to bring their children to the dentist. Unfortunately, carelessness or the importance that parents give to deciduous teeth, in some occasions the asymptomatic stage of a disease, causes that caregivers do not look for dental assistance when required to treat the disease (Zambrano et al., 2015).

In general, mothers with higher family incomes are better informed and can afford control over their children in every aspect. Thus, the involvement in their children's school activities might be heavily modulated by socioeconomic status (Piovesan et al., 2017). In a systematic literature review, socioeconomic status, family structure, overcrowded homes and number of children were significant predictors for children's OHRQoL (Kumar, 2017).

As an example, caregivers with a higher level of education are more aware of the signs and symptoms of oral conditions in their children. A similar pattern of association was recently reported concerning caregivers' health knowledge, where higher health literacy was associated with an increase in oral reports of "problems" related to their children's health (Kragt et al., 2018). Moreover, according to the literature, data has revealed lower levels of child impact in parents/caregivers with a higher schooling level, compared to children from families with a lower schooling level. In the overall population, parents' higher level of schooling is associated with better OHRQoL of children (Vollu, 2018).

Regarding the caregivers' psychological aspects, mothers with low or little ability to adapt to stressful situations are more likely to have children with caries (Gomes et al., 2018).

Regarding home environment, higher levels of any religious practice might be associated with a better psychological well-being and satisfaction with life among young people. Some studies have reported the association of religiousness with oral health in children and adults. Families with religious beliefs show lower levels of caries and periodontal diseases. Furthermore, clinical findings have shown an association between religious practice and self-perception of oral health, which proves that frequent religious practice was a protecting factor regarding the perception of regular or bad oral health (Menegazzo et al., 2018).

Parents' age has been found to be unequally distributed between the cases and controls. For example, parents under thirty years old are three times more likely to have an impact on OHRQoL than their counterparts. The reason for this is that younger parents/caregivers might have less professional stability (35 years old or less), less experience in child care, which might contribute to a feeling of insecurity (Firmino et al., 2016).

Regarding the child's sex, when analyzed specifically, according to some studies, parents with daughters show higher concern regarding their daughters' OHRQoL, compared to parents with sons. Boys internalize their problems and afflictions, and do not express them as much as girls, thus leaving their parents less concerned (Vollu et al., 2018). Another study showed that males were less tolerant to oral symptoms than females (Sun et al., 2017).

A contextual factor is public schools versus private schools. One study revealed that children that attend public schools showed a higher impact on OHRQoL, than those who attend private schools (Gomes et al., 2018). The school environment is important for children's intellectual development, which also influences health behaviors. On the other hand, there is a relation between economic level and type of preschool that the child attends (Piovesan et al., 2017).

\section{EVIDENCE IN CHILE}

According to ENCAVI (Quality of Life and Health Survey) 2015-2016, conducted nationally, there is a good self-perception of QoL and health. However, the distribution by sex, age and educational level is unequal. Women, older people and people with a lower educational level present worse assessments of their QoL and health status. The knowledge of OHRQoL might help to improve the development of programs and the effectiveness of oral health services, since it allows the assessment of small children, perceived needs and effectiveness of treatment strategies.

A study conducted in Santiago, showed that the caregiver's perception about the child's OHRQoL is affected negatively by "pain in the teeth, mouth or maxillary bones in 41\%" (González et al., 2018). The results of this study revealed that, regarding the group "child impact", the most affected variables were pain in the teeth, mouth or maxillary bones and difficulty for eating. This is directly related to the group "family impact", where the most affected variable was parents' feeling of guilt. Different stu- 
dies have tried to establish a link between the parents'/caregivers' degree of guilt in relation to their children's oral health.

Another study with parents/caregivers of preschool aged children between the ages of 3 and 5 in Santiago showed that the caregiver's perception about the child's QoL is negatively affected by "pain in the teeth, mouth or maxillary bones (41\%)". In contrast, the study didn't show that they "avoided speaking (2\%)". The option "I don't know" obtained the lowest percentage overall, which determines that all questions were understood and a response was possible (González et al., 2018). Regarding the group "child impact", the most affected variables were pain in the teeth, mouth or maxillary bones and difficulty for eating. This is directly related to the group "family impact" where the most affected variable was parents' feeling of guilt. Different studies have tried to establish a link between parents'/caregivers' degree of guilt in relation to their children's oral health. In this regard, apparently only oral conditions that cause pain, such as cavitary lesions, might predict parents' guilt and they assume that the absence of pain in their children is a sign of good oral health (González et al., 2018).

Finally, another study revealed that oral health has an influence on the quality of life of schoolchildren between the ages of 11 and 14 in Licantén. The impacts were prevalent, although non severe, and are mainly related to difficulties for eating, smiling and brushing teeth. This proves that dental problems might interfere with the performance of daily activities (Moreno et al., 2014).

\section{REFERENCES}

Åkesson ML, Wärnberg Gerdin E, Söderström U, Lindahl B, Johansson I. Health-related quality of life and prospective caries development. BMC Oral Health. 2016;16:15.

Ashari A, Mohamed A. Relationship of the Dental Aesthetic Index to the oral health-related quality of life. Malaysia. Angle Orthod. 2016;86(2):337-342.

Basavaraj P, Sunil M, Nagarajappa R, Ashish S, Ramesh G. Correlation between oral health and Child-OIDP index in 12- and 15-year-old Children from Modinagar. Asia Pac J Public Health. 2013;26(4):290-400.

Born C, Divaris K, Zeldin L, Rozier R. Influences on preschool children's oral health-related quality of life as reported by English and Spanish speaking parents and caregivers. J Public Health Dent. 2018;76(4):276-286.

Cancio V, Faker K, Baccin C, Paiva S, Almeida M. Individuals with special needs and their families' oral health-related quality of life. Braz Oral Res. 2018;32.

Correa P, Paixao S, Martins S, Martins P, Goncalves R, Silva L, Ramos M. Dental caries, but not malocclusion or developmental defects, negatively impacts preschoolers' quality of life. Brazil. Int J Paediatric Dent. 2016;26(1):211-219.

De Melo N, Jefferson R, Saliba C, Costa W. Socioeconomic level and the parents' perception of the impact of oral diseases on their children's quality of life. Braz J Oral Sci. 2016;32(2):135-139.

Feitosa S, Colares V, Pinkham J. The psychosocial effects of severe caries in 4-year-old children in Recife, Pernambuco. Brazil Cad Saúde Pública. 2005;21(5):1550-1556.

Firmino R, Gomes M, Viera-Andrade R, Martins C, Paiva S, GranviIle-Garcia A. Case- control study examining the impact of oral health problems on the quality of life the families of preschoolers. Braz Oral Res. 2016; 30(1):1-9.

Galván M. ¿Que es calidad de vida? México: Universidad autónoma del estado de Hidalgo; 2015.

Gomes M, Neves E, Perazzo M, Paiva S, Ferreira F, Granville-Garcia A. Contextual. Individual determinants of oral health-related quality of life among five-year-old children: a multilevel analysis. Peer J. 2018;31:3-17.

González E, Ugalde C, Valenzuela L, Guajardo G. Application of the early childhood oral health impact scale in Chilean preschoolers. Rev Clin Periodoncia Implantol Rehabil Oral. 2018;11(1):9-12.

Kragt L, Wolvius E, Raat J, Jaddoe V Ongkosuwito E. Social inequalities in children's oral health-related quality of life: the generation R study. Quality Life Res. 2018;26(12):3429-3437.

Kramer PF, Feldens CA, Ferreira SH, Bervian J, Rodrigues PH, Peres MA. Exploring the impact of oral diseases and disorders on quality of life of preschool children. Community Dent Oral Epidemiol. 2013;41(4):327-35.

Kumar S, Zimmer-Gembeck MJ, Kroon J, Lalloo R, Johnson N. The role old parental rearing practices and family demographics on oral health-related quality of life in children. Quality Life Res. 2017;26(8): 2229-2236.

Menegazzo G, Sfreddo C, Marquezan P, Ramadan Y, Ardengui T. Family religiosity and oral health related quality of life: a multilevel analysis in Brazilian schoolchildren. Braz Dent J. 2018;29(4):381-387.

Monte-Santo A, Viana S, Moreira K, Bonini G, Mendes F, Imparato J. Prevalence of eraly loss of primary molar and its impact in schoolchildren's quality of life. Int J Paediatr Dent. 2018; 28(6):595-601.

Moreno X, Vera C, Cartes-Velásquez R. Impacto de la salud bucal en la calidad de vida de escolares de 11 a 14 años, Licantén, 2013. Rev Clín Periodoncia Implantol Rehabil Oral. 2014;7(3):142-148.

Perazzo M, Gomes M, Neves E, Martins C, Paiva S, Granville-Garcia A. Oral health- related quality of life and sense of coherence regarding the use of dental services by preschool children. Int J Paediatr Dent. 2016;27(5):334-343.

Piovesan C, Ardenghi T, Mendes F, Agostini B, Michel-Crosato E. Individual and contextual factors influencing dental health care utilization by preschool children: a multilevel analysis. BMC Oral Health. 2017;16(5): 2-10.

Sheiham A. Dental caries affects body weight, growth and quality of life in pre-school children. Br Dent J. 2006;201(10):625-626.

Sun L, Wong M, McGrath C. The factors that influence the oral health-related quality of life in 12-year-old children: baseline study of a longitudinal research. Health Qual Life Outcomes. 2017;15(1):1-14.

Urzúa A, Caqueo A. Quality of life: A theoretical review. Ter Psicol. 2012;30(1):61-71.

Vollu A, Da Costa M, Maia L, Fonseca-Goncales A. Evaluation of oral health-related quality of the life to assess dental treatment in preschool children with early childhood caries a preliminary study. J Clin Pediatr Dent. 2018;42(1):37-44.

Zambrano 0, Fong L, Rivera LE, Calatayud E, Hernández JA, Maldonado A, Rojas-Sánchez F, Principe S, Pérez G, Navarro T, Acevedo AM. Impact of early childhood caries on the quality of life of the Zulian child and his family. ODOUS Cient. 2015;16(2):98-101. 